\title{
Artritis por Cryptococcus neoformans en un adulto mayor: Presentación de un caso y revisión
}

\author{
Germán Gil L., Carolina Foster B., Oscar Neira Q., Sergio Palma C., Javier Basualdo A., \\ Carolina Heredia P., Alejandra Fernández V., Chrystal Juliet L. y Juan C. Tapia A.
}

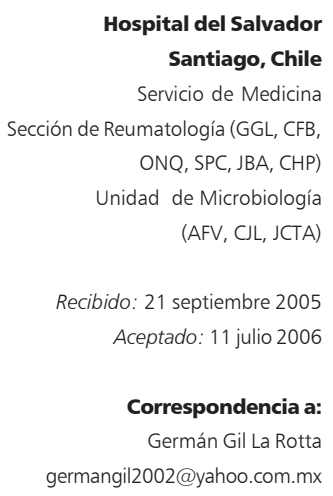

\section{Introducción}

$\mathrm{L}$ a criptococcosis es una infección exógena, cosmopolita, de evolución subaguda o crónica, que afecta principalmente a pacientes inmunocomprometidos y cuyo agente es Cryptococcus neoformans, una levadura capsulada que pertenece a los Basidiomicetos ${ }^{1}$.

Cryptococcus neoformans se adquiere por inhalación de las levaduras desecadas existentes en la naturaleza y se disemina por vía hematógena a diferentes órganos y tejidos. La fase inicial puede ser asintomática $^{1,2}$.

Suele afectar preferentemente al SNC dando lugar a meningitis de presentación subaguda; en algunas ocasiones puede comprometer otros órganos, incluyendo el sistema osteoarticular en alrededor de $10 \%$ de los $\operatorname{casos}^{1,3-5}$

Se presenta un caso de artritis criptococócica diagnosticado en nuestro hospital, dado que es una manifestación inusual de criptococcosis y se efectúa una revisión de la literatura.

\section{Caso clínico}

Mujer de 92 años de edad, con antecedentes de histerectomía y salpingectomía bilateral, a los 20 años de edad por tuberculosis genital y peritoneal. Además padeció de un linfoma gástrico antral efectuándosele una gastrectomía subtotal aproximadamente a los 40 años de edad, no recidivado. Residía en la zona urbana de Santiago de Chile, en una vivienda de construcción sólida, donde alimentaba palomas que habitaban en el jardín.

Ingresó al Hospital Del Salvador, trasladada de un centro geriátrico en el cual había consultado un mes antes por un cuadro de dos meses de evolución de dolor e inflamación en la rodilla derecha con importante limitación funcional, sin fiebre ni historia de traumatismo reciente. Traía una radiografía de rodilla derecha tomada al inicio de su enfermedad, que mostraba discreta disminución del espacio fémoro-rotuliano.

En el examen físico de ingreso se apreciaba una paciente enflaquecida, con hemodinamia estable, afebril, P. arterial $160 / 80 \mathrm{~mm} \mathrm{Hg}$, pulso 78/min, F. respiratoria $22 / \mathrm{min}$, y un aumento de volumen en la rodilla derecha con eritema, calor local, rigidez y limitación funcional importante. Las otras articulaciones estaban indemnes. Exámenes de laboratorio: hematocrito: 32\%, leucocitos: 7.000 céls $/ \mathrm{mm}^{3}$, VHS $83 \mathrm{~mm} /$ hora, PCR 56 $\mathrm{mg} / \mathrm{dl}(\mathrm{VN}<5 \mathrm{mg} / \mathrm{dl})$; glicemia $114 \mathrm{mg} / \mathrm{dl}$, albuminemia $3,6 \mathrm{~g} / \mathrm{dl}$, creatininemia $0,8 \mathrm{mg} / \mathrm{dl}$, enzimas hepáticas normales, protrombinemia $100 \%$, serología para VIH negativa (ELISA Abbott ${ }^{\mathrm{MR}}$ ). Por la presencia de una monoartritis se le realizó una artrocentesis obteniéndose sólo $1 \mathrm{ml}$ de líquido sinovial de aspecto turbio. El recuento celular fue de 32.000 céls $/ \mathrm{mm}^{3}$ sin presencia de cristales. El estudio microbiológico de este líquido articular incluyó examen directo con tinción de Gram, cultivo en agar sangre, agar chocolate, caldo tioglicolato, caldo cerebro-corazón y medio de LowensteinJensen para estudio de micobacterias. En la tinción de Gram directa no se observaron bacterias ni elementos 
levaduriformes. A las 48 horas se constató en los agares sangre y chocolate el crecimiento de colonias mucosas y brillantes, de color crema, que fueron identificadas como $C$. neoformans mediante las pruebas bioquímicas de ureasa, el sistema API para levaduras 20C AUX (Biomérieux, Francia) y el panel RapID Yeast Plus (Remel). Dado el hallazgo inhabitual se solicitó una segunda muestra de líquido articular para confirmar el diagnóstico, la que fue obtenida 7 días después de la primera punción, extrayéndose sólo una gota de líquido articular que fue sembrada en un frasco de hemocultivo automatizado (Becton Dickinson) y medio de Sabouraud; nuevamente se apreció el crecimiento de levaduras a las 48 horas de incubación (Figura 1). Del frasco de hemocultivo se realizó tinción de Gram y tinta china (Figuras 2 y 3).

Simultáneamente se recolectaron dos nuevas muestras de sangre para cultivos automatizados, desarrollándose el mismo microorganismo a los 18 días de incubación. Una muestra de suero para la detección de antígeno de Cryptococcus mediante técnica cualitativa de látex (Remel), dio resultado positivo.

Se determinó la susceptibilidad in vitro a anfotericina $\mathrm{B}$, fluconazol, itraconazol y ketoconazol mediante la técnica de difusión en agar con tabletas Rosco en medio de Shadomy y por E-Test ${ }^{\mathrm{MR}}$, resultando susceptible a todos los agentes antifúngicos estudiados. Las CIM fueron: fluconazol $1,0 \mu \mathrm{g} / \mathrm{ml}$ a las $24 \mathrm{~h}$ y $2,0 \mu \mathrm{g} / \mathrm{ml}$ a las $48 \mathrm{~h}$; itraconazol $0,094 \mu \mathrm{g} / \mathrm{ml} \mathrm{y}$ ketoconazol $0,016 \mu \mathrm{g} / \mathrm{ml}$ a las 24 y $48 \mathrm{~h}$ respectivamente y anfotericina B $0,125 \mu \mathrm{g} / \mathrm{ml}$ a las $24 \mathrm{~h}$ y $0,250 \mu \mathrm{g} / \mathrm{ml}$ a las $48 \mathrm{~h}$.

La evolución radiológica evidenció importante pérdida del espacio fémoro-tibial en dos meses, con algunas pequeñas imágenes erosivas en los márgenes articulares y un acentuado aumento de partes blandas. (Figura 4).

Al octavo día de su ingreso, y una vez conocida la susceptibilidad in vitro de la cepa, se inició tratamiento con fluconazol oral $200 \mathrm{mg} /$ día; al mismo tiempo se le realizó una artroscopia que evidenció proliferación sinovial importante, practicándose sinovectomía parcial y biopsia. La histopatología evidenció un proceso inflamatorio crónico granulomatoso con células gigantes de tipo cuerpo extraño y fragmentos de tejido óseo necrótico (Figura 5a). Se observó un infiltrado tisular con abundantes microorganismos redondos y ovales de aproximadamente 7,5 a $10 \mu$, positivo para tinción de mucicarmin (Figura 5b). En el cultivo de estas muestras de tejido sinovial también creció $C$. neoformans.

Se excluyó la existencia de un foco clínico pulmonar mediante TAC de tórax y de un foco endocárdico con ecocardiograma trans-esofágico. Se intentó obtener
LCR para estudio pero la punción lumbar fue frustra. Se realizó además estudio para descartar TBC osteoarticular, con RPC y cultivo para Mycobacterium en tejido sinovial, y test de tuberculina (PPD), todos con resultado negativo. Se practicó durante la hospitalización una endoscopia digestiva alta y biopsia sin evidencia de recidiva del linfoma gástrico.
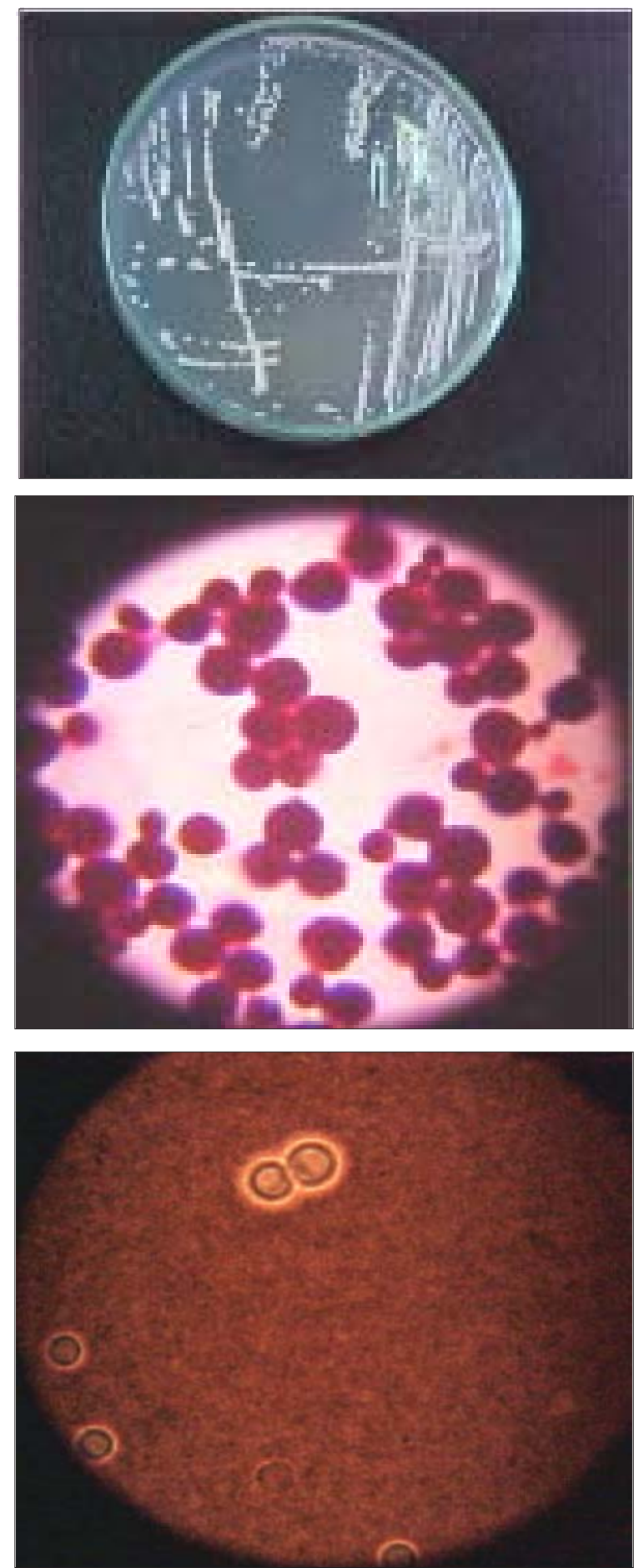

Figura 1. Colonias de Cryptococcus sp en medio de Sabouraud.

Figura 2. Se observan abundantes estructuras levaduriformes a la tinción de Gram.

Figura 3. Levaduras capsuladas con tinción de tinta china recuperadas desde el frasco de hemocultivo con líquido articular. 
Figura 4. Evolución radiológica de la rodilla derecha.

Figuras $\mathbf{5 a}$ y $\mathbf{5 b}$. Biopsia de sinovial: 5a.Tejido con células gigantes de tipo cuerpo extraño, trabécula ósea desvitalizada y Cryptococcus sp (tinción de HE 200x). 5b. Cápsula del microorganismo en rojo y células gigantes de tipo cuerpo extraño (tinción de mucicarmin, 400x)
Al quinto día de ingreso presentó alza febril y un urocultivo con Proteus mirabilis sensible a ceftriaxona, con la cual fue tratada durante 7 días con buena respuesta y luego se mantuvo afebril. Con posterioridad a la artroscopia e inicio del tratamiento médico presentó regresión importante de lo signos inflamatorios de la rodilla derecha y recuperación de la movilidad. Se dio el alta hospitalaria a las 3 semanas de tratamiento



1 mes de evolución

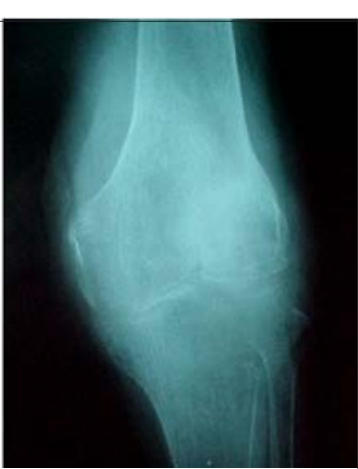

3 meses de evolución

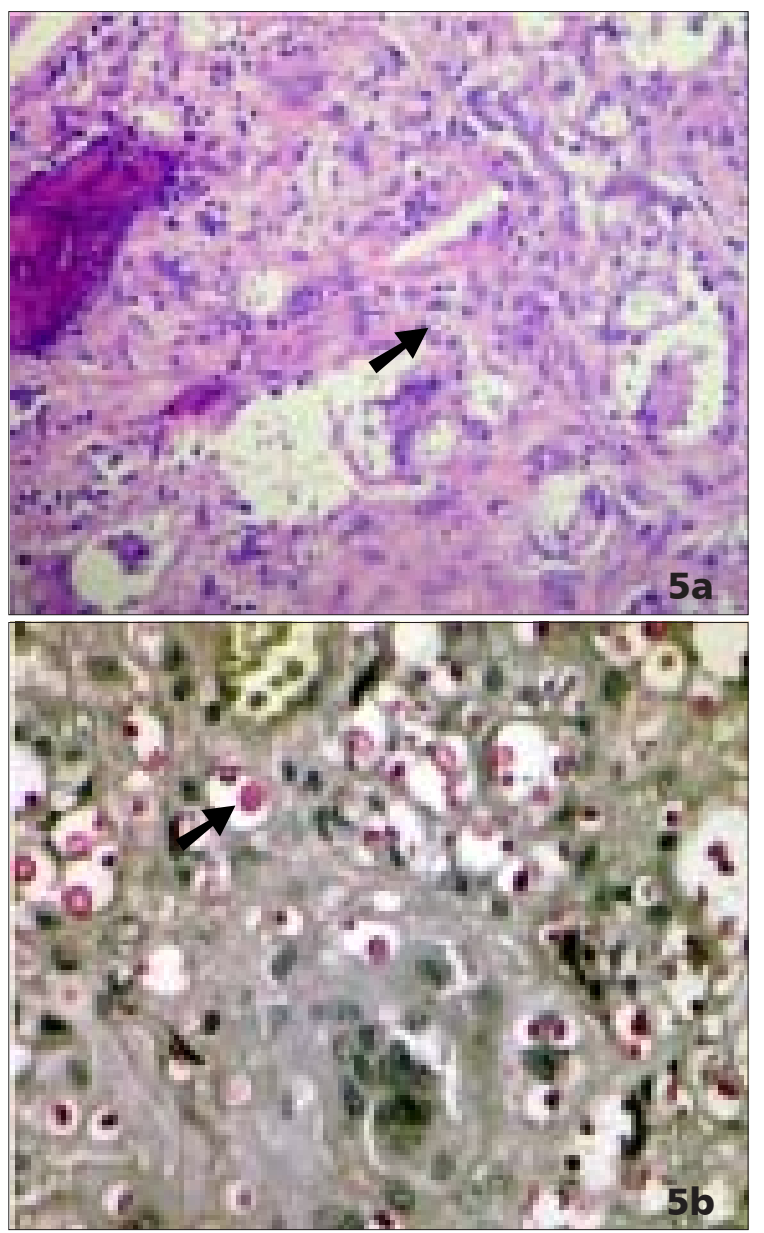

antifúngico, con indicación de mantener fluconazol oral hasta completar 6 meses. Abandonó los controles tomándose conocimiento de su fallecimiento en domicilio, 3 meses después, por causa desconocida.

\section{Discusión}

La criptococcosis es una micosis sistémica producida por la forma levaduriforme asexuada del hongo teleomórfico Filobasidiella neoformans, perteneciente a la familia Basidiomicetos, denominado Cryptococcus neoformans ${ }^{6}$. Los criptococos son levaduras capsuladas redondas u ovales $(3,5-8 \mu)$, que se reproducen por yemación única. Poseen una cápsula polisacárida que constituye uno de sus factores de virulencia, pues protege al hongo de la fagocitosis ${ }^{2}$. Tienen metabolismo aerobio y producen ureasa. Aunque existen 19 especies dentro del género Criptococcus, la mayoría de las enfermedades en los humanos son ocasionadas por la especie neoformans, siendo muy infrecuentes los casos publicados por las especies laurentii y albidus. Por muchos años en los laboratorios clínicos se ha utilizado la clasificación serológica basada en los antígenos capsulares que demuestra 5 variedades: los serotipos A, B, C, D y AD. Cryptococcus neoformans var. neoformans incluía los serotipos A, D y AD, y la var gattii los serotipos B y C. El uso actual de métodos de mapeo genético del ADN ha propuesto cambiar la designación de variedades por tres especies, de la siguiente manera: $C$. neoformans constituida por el serotipo D; C. grubii serotipo A; y C. gattii, que incluye los serotipos $\mathrm{B}$ y $\mathrm{C}$, pasaría a constituir una nueva especie llamada bacilospora. Las cepas de serotipo híbrido AD no han sido incluídas en ninguna de estas especies aún ${ }^{7,9-11}$

Meyer y cols, utilizando técnicas de biología molecular en un estudio multicéntrico, recolectó 340 cepas de $C$. neoformans de aislados clínicos de procedencia humana, veterinaria y ambiental, de 9 países iberoamericanos, incluyendo Chile con 19 cepas ( 15 clínicas y 4 ambientales). El estudio describió los mismos 8 tipos moleculares previamente conocidos, siendo la variedad VNI la más frecuente $(68,2 \%)$ correspondiente a $C$. grubii, serotipo A, descrito como el prevalente en infecciones humanas en todo el mundo. El resto de las variedades fueron poco frecuentes (menor a 6\%). Destacó una interesante similitud entre las cepas de España y Chile siendo del tipo molecular VNIII, serotipo híbrido $\mathrm{AD}$, planteando los autores que los Cryptococcus presentes hoy en América del Sur fueron introducidas durante la colonización europea ${ }^{7}$. Por otra parte, Díaz y cols no encontraron C. neoformans var. gattii en 18 cepas chilenas ( 9 de infecciones humanas 
y 9 de deyecciones de aves) mediante técnica de cultivo con agar específico, canavanina-glicina-azul de bromotimol $^{8}$.

Las criptococcosis producidas por las especies neoformans y grubii son de distribución geográfica universal, tienen como hábitat las excretas antiguas y desecadas de palomas y otros pájaros y afectan en mayor grado a pacientes inmunocomprometidos; en cambio, la especie $C$. gattii se ha encontrado en zonas tropicales y subtropicales donde existen distintas especies de eucaliptus (Eucaliptus camaldulensi, Eucaliptus rudis), como en Australia y Brasil, y tiene predilección por pacientes sin compromiso inmune ${ }^{1,6}$.

La infección por C. neoformans es una enfermedad infrecuente que se presenta principalmente en pacientes con compromiso de la inmunidad de tipo celular (ej: pacientes con neoplasias, lupus eritematoso sistémico, trasplantes de órganos sólidos o precursores hematopoyéticos, tratamiento con corticoesteroides u otra medicación inmunosupresora, diabetes mellitus, sarcoidosis, etc $)^{4}$.

Otras condiciones asociadas a criptococcosis son el síndrome de hiper-IgM en niños y adultos con linfopenia T CD4 y serología para VIH negativa; incluso el hábito al tabaco puede predisponer a infección por criptococo en ciertos individuos ${ }^{12}$.

Antes de la epidemia de SIDA la incidencia de criptococcosis en E.U.A. era menor de 1 caso por millón de habitantes. En 1980 la criptococcosis emergió como una infección oportunista ocurriendo entre 5 y $10 \%$ de pacientes con SIDA en E.U.A., Europa y Australia, mientras que en Sudamérica y África estos porcentajes aumentaron a $10-30 \% \%^{2,11}$. Ochenta a $90 \%$ de los casos de criptococcosis se presentan en pacientes con SIDA, cuando la inmunodepresión es grave y en proporción inversa al recuento de linfocitos T CD4, siendo mayor el riesgo cuando los valores son inferiores a 100 céls $/ \mathrm{ml}$. En general, el recuento promedio de linfocitos CD4 en pacientes infectados por VIH con criptococcosis se ha estimado en 73 céls $/ \mathrm{ml}^{12}$. Sin embargo, la infección por Cryptococcus sp ha disminuido hasta en $75 \%$ con la introducción de la triterapia y el uso de fluconazol para tratar la candidiasis orofaringea, y profilaxis contra meningitis criptococóccica en estos pacientes $^{11,12}$. En Atlanta, E.U.A., la incidencia de criptococcosis en pacientes con infección por VIH descendió de 66 casos por 1.000 pacientes en 1993 a 7 casos por 1000 en el año $2000^{11}$.

El compromiso óseo es poco frecuente en pacientes con SIDA ${ }^{5}$. Después de Candida sp y Aspergillus sp, C. neoformans es el hongo más frecuentemente aislado en micosis profundas asociadas a inmunosupresión, teniendo una peculiar predilección por pacientes que reciben corticoesteroides ${ }^{1,5,11}$. En una serie de 306 pa- cientes no infectados por VIH, con criptococcosis, el factor predisponente fue el uso de corticoesteroides en $28 \%$, seguido por neoplasias y trasplante de órganos en $18 \%$, respectivamente, mientras que $13 \%$ presentaba alguna enfermedad reumatológica ${ }^{11}$. Análisis retrospectivos realizados en la Universidad de Texas en el Centro de Cáncer M.D. Anderson, Houston, entre 1989 y 1999, revelaron una incidencia de 18 casos por 100.000 admisiones por neoplasias ${ }^{12}$. Se ha visto que neoplasias hematológicas como el linfoma y la leucemia crónica tienen mayor riesgo de criptococcosis $^{6}$.

La vía de infección habitual es por inhalación de las levaduras desecadas $(<3 \mu)$ existentes en la naturaleza, y raramente por inoculación, de forma que la puerta de entrada es el tracto respiratorio, produciéndose en la mayoría de casos una infección pulmonar asintomática y autolimitada. La diseminación ocurre principalmente hacia el SNC; aunque también se puede localizar en piel, ojo, hígado, riñón, bazo, ganglios linfáticos, glándulas suprarrenales y próstata ${ }^{1,12}$. Otras localizaciones menos frecuentes son: miocárdica, tracto genitourinario y gastrointestinal, músculo, mama, tiroides y compromiso osteoarticular ${ }^{1,12}$. Este último se presenta en 5 a $10 \%$ de los casos, generalmente es adquirido por vía hematógena con invasión del tejido sinovial y se manifiesta como osteomielitis ${ }^{13}$. Las lesiones se localizan principalmente en los huesos del cráneo, costillas, pelvis y epífisis de los huesos largos o vértebras ${ }^{1,3-5,14}$. A pesar de la tendencia de esta levadura a causar infección diseminada en ciertos pacientes, la artritis criptococóccica es una entidad extremadamente rara y, suele reportarse como casos aislados. Garau et $\mathrm{al}^{1}$ en una revisión de 25 casos de artritis criptococóccica no reporta casos en adultos mayores.

La afección articular puede manifestarse como inflamación de tejidos blandos, invasión, y destrucción cartilaginosa u ósea, en semanas a meses de evolución. La articulación más frecuentemente afectada es la rodilla, aunque pueden afectarse otras, e incluso pueden comprometerse varias articulaciones simultáneamente ${ }^{1}$.

La biopsia puede mostrar tejido óseo desvitalizado, reacción subperióstica e inflamación crónica compuesta por histiocitos, formando células gigantes de tipo cuerpo extraño, además de abundantes microorganismos redondos u ovales de 7,5 a $10 \mu \mathrm{m}$, positivos para tinciones de plata y mucicarmín, demostrando su cápsula ${ }^{5}$.

Existe evidencia que la inmunidad humoral protege contra C. neoformans ${ }^{12}$. El adulto mayor presenta una serie de cambios en su inmunidad, conocidos como inmunosenescencia que consisten en una disregulación del sistema inmune y se manifiesta en una menor capacidad de respuesta inmunológica tanto celular 
como humoral, lo cual explica el incremento de las infecciones, neoplasias y fenómenos autoinmunes a esta edad $^{15}$.

El retraso en el diagnóstico de artritis por $C$. neoformans es un hecho frecuente, probablemente debido a que una infección fúngica raramente se sospecha en el diagnóstico de una monoartritis, presenta un curso insidioso y responde sintomática y parcialmente al tratamiento con AINES ${ }^{1}$. En el caso presentado, el retraso fue de tres meses.

El diagnóstico etiológico se establece con el examen microscópico directo, en el que se observan típicas levaduras capsuladas ${ }^{2}$, la tinción con tinta china que destaca la cápsula que no se impregna con el colorante, y el cultivo. El medio de cultivo más apropiado es el agar Sabouraud sin cicloheximida, desarrollándose además en agar sangre, agar chocolate y caldos utilizados de rutina en el estudio microbiológico del líquido articular. A las 48 a 72 horas de incubación, es posible observar colonias de aspecto mucoso, aunque con el tiempo pueden aparecer secas, siendo el color variable (crema, ocre, rosa, amarillo) ${ }^{2}$.

También apoya el diagnóstico la detección de antígenos capsulares en fluidos biológicos (principalmente LCR, suero, orina, lavado broncoalveolar) a través de una prueba de aglutinación de látex. Diluciones mayores de 1:4 sugieren infección por Cryptococcus ${ }^{1}$; mientras que el descenso en los títulos sirve como parámetro para seguir la evolución y respuesta al tratamiento $^{1,6,16}$. Se han descrito resultados falsos positivos debidos a la presencia de factor reumatoide, reacciones cruzadas con el polisacárido de otros microorganismos como Trichophyton beigelii y Capnocytopaga canimorsus o contaminación de las placas donde se realiza la prueba con agar o agarosa. Los falsos negativos pueden ocurrir en la etapa precoz de una infección, por fenómeno de prozona (= exceso de antígeno que inhibe la reacción Ag-Ac), presencia de complejos inmunes, cepas de $C$. neoformans con poca cápsula o de pacientes con criptococcosis pulmonar sin diseminación hematogena ${ }^{2,5,6,12}$.

La radiografía en osteomielitis muestra lesiones osteolíticas, caracterizadas por márgenes bien definidos, esclerosis ósea periférica leve y poca o ninguna reacción perióstica. Estos hallazgos también pueden presentarse en tuberculosis ósea o neoplasias como mieloma, metástasis de cáncer pulmonar, mama, riñón, próstata, tiroides, tracto gastrointestinal y melanoma, con los cuales hay que hacer un diagnóstico diferencial. En la artritis hay aumento de partes blandas y destrucción de hueso y cartílago ${ }^{4,5}$.

La artritis criptococóccica requiere un tratamiento combinado médico y/o quirúrgico ${ }^{4}, \mathrm{y}$ siempre que sea posible, será necesario controlar adecuadamente los factores predisponentes y enfermedades de base. Los procedimientos invasores incluyen artrocentesis y eventualmente sinovectomía ${ }^{5,13}$.

La terapia médica incluye el uso de antifúngicos como anfotericina $\mathrm{B}$, asociada o no a 5-fluocitosina (no disponible en Chile) y azoles como fluconazol, itraconazol y voriconazol ${ }^{11,13,17,18}$. Este último ha demostrado tener buena actividad in vitro contra $C$. neoformans y puede ser usado con buena respuesta en algunos casos de criptococcosis refractaria ${ }^{11,12}$.

En pacientes inmunocompetentes con criptococcosis leve a moderada, con compromiso pulmonar y sin compromiso del SNC, se recomienda como primera elección, tratar con fluconazol 200-400 mg/día por 6 a 12 meses $^{6}$. De segunda línea itraconazol 200-400 mg/ día por 6-12 meses o anfotericina $\mathrm{B}$ dosis de $0,5-1 \mathrm{mg} /$ $\mathrm{k} /$ día (total 1.000-2.000 mg) ) $^{6,18}$.

Para pacientes con enfermedad más grave, como osteomielitis criptococóccica, las alternativas son anfotericina B $0,5-1 \mathrm{mg} / \mathrm{kg} /$ día, con o sin fluocitosina $100 \mathrm{mg} / \mathrm{kg} /$ día, por 6-10 semanas ${ }^{13,17}$. En la década del 90 con la introducción de los nuevos azoles aparecieron los primeros reportes de infecciones osteoarticulares fúngicas tratadas con itraconazol o fluconazol, con buenos resultados; sin embargo, no se establece una comparación de su efectividad con anfotericina $\mathrm{B}^{17}$. Al respecto Pérez-Gómez et al en una revisión de 56 casos de infecciones osteoarticulares fúngicas, 37 tratadas con itraconazol y 19 con fluconazol, obtuvieron buena respuesta en 31 y 17 casos respectivamente. En un caso de osteomielitis por Cryptococcus sp tratada con itraconazol $200 \mathrm{mg} /$ día y otro de artritis de rodilla con fluconazol $800 \mathrm{mg} /$ día por 6 semanas y sinovectomia, el tratamiento fue exitoso ${ }^{17}$. Pese a esto concluyeron que es difícil establecer el rol de los nuevos azoles dados los pocos casos reportados. En pacientes no críticos el fluconazol podría ser una alternativa de primera línea en artritis por Candida sp o Cryptococcus sp, e itraconazol en infecciones osteoarticulares por Blastomyces dermatitidis o Aspergillus $\mathrm{sp}$, mientras que en pacientes críticos la terapia de elección es anfotericina B con otro antifungico, y continuar con fluconazol o itraconazol una vez tratada la fase aguda ${ }^{17}$. El uso de azoles para tratar artritis $u$ osteomielitis implica dar altas dosis por la baja penetración en tejido óseo, dosis que pueden darse al menos por 6 semanas dado su amplio rango terapéuti$\mathrm{co}^{17}$. Sin embargo, existen reportes aislados de osteomielitis criptococóccica tratados con fluconazol $200 \mathrm{mg}$ día por 10 semanas $^{19}$, o con la asociación fluconazol y fluocitosina con buena respuesta; esta última alternativa podría ser útil en pacientes con azoemia o alteraciones hidroelectoliticas ocasionadas por el uso de anfotericina $\mathrm{B}^{13}$. 
En pacientes sin SIDA ni neoplásicas, la tasa de mortalidad por infecciones criptococóccicas es de $\sim 25$ a $30 \%$. Luego del tratamiento inicial, pueden recaer 20 a $25 \%$ de los pacientes ${ }^{6}$. En casos de hospederos inmunocomprometidos, la mortalidad puede alcanzar a $10-15 \%$ durante la terapia inicial, con recaídas en hasta $60 \%$ de ellos y una mortalidad entre 30 y $60 \%$ en los 12 meses siguientes 6 .

En este caso, se evaluó en conjunto con Infectología el riesgo/beneficio de administrar anfotericina B. Por su avanzada edad y por no ser una paciente en estado crítico se optó por emplear fluconazol. Con el tratamiento médico y quirúrgico realizado se observó una respuesta clínica, con alivio importante del dolor e inflamación.

\section{Comentario final}

La artritis por $C$. neoformans es una enfermedad infecciosa infrecuente, que se presenta principalmente en pacientes inmunocomprometidos y como manifestación de diseminación hematógena. A pesar ser una entidad rara es importante considerarla dentro del diag- nóstico diferencial de monoartritis crónica en este tipo de pacientes, pues requiere tratamiento médico $\mathrm{y} / \mathrm{o}$ quirúrgico específico. Con respecto al estudio microbiológico, cabe destacar que la confirmación microbiológica puede realizarse aún con una muy escasa cantidad de líquido sinovial.

\section{Resumen}

La infección por Cryptococcus neoformans es infrecuente, los sitios más comunes de presentación son pulmón y SNC. La osteomielitis criptococóccica ocurre en 5 a $10 \%$ de los pacientes con criptococcosis diseminada. La mayoría de casos ocurre entre 21 y 59 años de edad, hay pocos reportes de artritis criptococóccica en adultos mayores.

\section{Agradecimientos}

A Loreto Tapia del Servicio de Anatomía Patológica del Hospital Del Salvador por la revisión de la histopatología y el aporte de las fotos de la biopsia.

\section{Referencias}

1.- Garau M, Del Palacio A. Artritis por Cryptococcus neoformans en receptor de trasplante renal. Rev Iberoam Micol 2002; 19: 186-9.

2.- Martín-Manzuelos E, Valverde-Conde A. Criptococosis: Diagnóstico microbiológico y estudio de la sensibilidad in vitro. Manual Control de Calidad SEIMC. Hospital Universitario Valme. Sevilla, 2000.

3.- Bosch X, Ramon R, Font J, Alemany X, Coca A. Bilateral cryptococcosis of the hip. A case report. J Bone Joint Surg Am 1994; 76: $1234-8$

4.- $\quad$ Tau Su Ch, Kuang Chen L, Feng Tsai Y, Jen Kuo Ch, Li Lu Ch. Case report: Disseminated cryptococcosis with pulmonary and marrow involvement mimicking radiological features of malignancy. J Chin Med Assoc 2004; 67: 89-92.

5.- Scully R E, Mark E J, McNeely W F, Ebelin S H, Phillips L D, Ellender S M. Case records of the Massachusetts General Hospital. Weekly clinico-pathological exercises. N Eng J Med 1999; 340: 1981-8.

6.- Cohen J, Powderly W G. Cryptococcosis. En Infectious Diseases, 2nd edition. New York NY, Elsevier 2004; 2353-7.
7.- Meyer W, Castañeda A, Jackson S, Huynh M, Castañeda E. Molecular typing of Iberoamerican Cryptococcus neoformans isolates. Emerg Infect Dis 2003; 9: 189- 95.

8. - Díaz M C, Sammann S. Estudio de variedades de Cryptococcus neoformans aisladas de muestras clínicas y deyecciones de aves en Santiago, Chile. Rev Arg Micología 1997; 20: $12-5$.

9.- Perfect J R. Cryptococcus neoformans. Mandell G L, Bennett J E, Dolin R, editors. Mandell, Douglas and Bennett's. Principles and Practice of Infectious Diseases. Sixth ed, 2005. Philadelphia: Churchill Livingstone, p. 2997-3012.

10.- Hazen K C, Howell S A. Candida, Cryptococcus and other yeasts of Medical Importance. Murray PR, Baron E, Pfaller MA, and Yolken RH. Manual of Clinical Microbiology. 8th ed. ASM Press, Washington DC; 2003; 1693-711.

11.- Bicanic T, Harrison T S. Cryptococcal meningitis. Br Med Bull 2004; 72: 99-118.

12.- Perfect JR, Casadevall A. Cryptococcosis. Infect Dis Clin North Am 2002; 16: 837-74.

13.- Cook P P. Succesful treatment of cryptococcal osteomyelitis and paraspinous abscess with fluconazole and flucytosine. South Med J 2001; 94: 936-40.
14.- Berhman R E, Masci J R, Nicholas P. Cryptococcal skeletal infections: case report and review. Rev Infect Dis 1990; 12 : 181-90.

15.- Marinovic M A. Cambios en la función inmune con la edad. Simposio problemas reumatológicos del adulto mayor. Rev Chil Reumatol 2004; 20: 51-2.

16.- Denning D, Kibbler Ch, Barnes R on behalf of the British Society for Medical Mycology. Review: British Society for Medical Mycology proposed standards of care for patients with invasive fungal infections. Lancet Infect Dis 2003; 3: 230-40.

17.- Pérez-Gómez A, Prieto A, Torresano M, Díez E, Mulero J, Labiano I, et al. Role of the new azoles in the treatment of fungal osteoarticular infections. Semin Arthritis Rheum 1998; 27: 226-44.

18.- Saag M S, Graybill R J, Larsen R A, Pappas P, Perfect J, et al. Practice guidelines for the management of cryptococcal disease. Infectious Diseases Society of America. Clin Infect Dis 2000; 30: 710-8.

19.- Murphy S N, Parnell N. Fluconazol treatment of cryptococcal rib osteomyelitis in an HIV-negative man. A case report and review of literature. J Infect 2005; 51: 30911. 